\title{
Application of Hybrid Teaching in English for Nursing in Higher Vocational Colleges
}

\author{
Suili Wang* \\ School of Health Science and Technology, Shanghai Sipo Polytechnic College, Pudong New Area, Shanghai 201300, China \\ *Corresponding author: Suili Wang, wangsuilijs@163.com

\begin{abstract}
With the rapid development and advancement of internet technology, "Internet Plus Education" has become a trend of basic education reform. It provides a new direction and thinking for English teaching in higher vocational nursing specialty. In teaching practice, higher vocational English teachers should be in line with the development trend of information education, use internet technology as teaching aids, assume the online and offline hybrid teaching mode, as well as further improve their learning initiative and enthusiasm while enriching the forms of teaching, so as to lay a good foundation for improving their comprehensive ability and professional quality. In regard to this, by analyzing the connotation of online and offline hybrid teaching, this paper explores the application strategies of hybrid teaching in English for nursing in higher vocational colleges in hope to provide some references for teachers.
\end{abstract}

Keywords: Hybrid teaching; English for nursing; Higher vocational colleges; Application strategies

Publication date: December 2021; Online publication: January 24, 2022

\section{Introduction}

At present, under the background of the rapid development of science and technology, higher vocational education has ushered in a new wave of development. Various network technologies have been widely used in teaching, thus effectively promoting the improvement of the teaching effect and talent training effect ${ }^{[1]}$. In this context, the efficiency of hybrid teaching is gradually revealed. As an online and offline hybrid teaching mode, it can realize the integrated development of traditional education and network education. It is also an important means to enhance students' learning interest. In the new era, teachers should actively explore the teaching characteristics of this model and apply it scientifically to English teaching for nursing in higher vocational colleges, so as to further improve the effect of English teaching and lay a solid foundation for the improvement of students' English skills and professional quality.

\section{Analysis of the connotation of hybrid teaching}

\subsection{Conceptual analysis}

Hybrid teaching mainly refers to an innovative teaching mode of knowledge education supported by internet technology through the integration of offline classroom and information-based teaching means. Compared with the single offline teaching mode, this mode of teaching maximizes the advantages of online education and creates a new hybrid teaching structure in the form of online and offline along with the innovation of teaching contents. Applying it to English teaching for nursing in higher vocational colleges expands students' learning. In that way, their learning will no longer be restricted by time and space; rather, their personalized learning needs and interest are met, along with the improvement in the flexibility of 
teaching. It can be seen that its application is extremely beneficial to the improvement of the teaching effect and the promotion of quality education ${ }^{[2]}$.

\subsection{Meaning analysis}

\subsubsection{Enriches teaching resources and expands curriculum capacity}

The application of hybrid teaching in English teaching for nursing in higher vocational colleges will gain richer and more colorful educational resources. In teaching practice, teachers should not only use traditional teaching materials and oral teaching methods to teach students relevant knowledge points, but combine pictures and video resources to further improve the curriculum capacity, so as to create an information teaching classroom ${ }^{[3]}$. For example, when designing the teaching plan, teachers should introduce some relevant information-based educational resources, such as pictures, micro classes, and small videos, so as to provide students with an interesting classroom experience, further improve their listening efficiency, and effectively improve their learning input.

\subsubsection{Promotes multi-party interaction and develops students' skills}

From an objective point of view, any teaching activity can be regarded as an interactive process, and English teaching for nursing in higher vocational colleges is no exception. This shows that in the teaching practice, teachers need to emphasize more on the design of interactive links and actively promote the interaction among themselves and students, so as to effectively improve the teaching practice. However, in consideration of the actual teaching situation, the interaction in English teaching for nursing in higher vocational colleges is inadequate, thereby putting forward higher requirements for teaching ideas and methods. How to carry out multi-party interaction in classroom teaching has become an urgent issue among teachers. The application of online and offline hybrid teaching mode can effectively solve this problem and expand classroom interaction in multiple dimensions. Specifically, in teaching practice, teachers should integrate the advantages of online education into offline education, build a three-dimensional curriculum interaction platform, as well as promote efficient and diversified interaction among teachers and students, which will inevitably stimulate students' learning enthusiasm and enable them to obtain more benefits in a relaxed learning environment ${ }^{[4]}$.

\subsubsection{Expands the teaching path and establishes good habits}

In the context of traditional educational concept, the classroom is the main place for teaching, and all teaching activities are carried out in the classroom. When students leave the classroom, it is difficult for them to receive teaching guidance, thus hindering the classroom effect to reach an ideal state. In order to break the limitations of time and space, it is imperative to implement hybrid teaching and apply online teaching methods to realize the extension of classroom teaching. At the same time, teachers can also create an autonomous and open learning platform for students based on their foundations in English, interests, and hobbies. Students need to be guided to carry out autonomous learning, in order to improve their learning effect and help them develop good learning habits ${ }^{[5]}$.

\section{Application strategies of hybrid teaching in English teaching for nursing in higher vocational colleges}

\subsection{Hybrid pre-class preview}

In English teaching for nursing in higher vocational colleges, pre-class preview has important practical significance for the development of classroom teaching in the future. It does not only help students grasp 
the teaching focus and improve their listening efficiency in classroom, but also enable them to improve their autonomous learning ability and independent inquiry ability, so as to lay a solid foundation for the development of their thinking and professional quality. As for the current English teaching for nursing in higher vocational colleges, most of them only offer simple preview tasks while some do not even have preclass preview tasks at all, resulting in the lack of effective preview feedback. Then again, students do not preview seriously, and the preview effect is poor. Therefore, in order to change this situation, teachers should focus on hybrid teaching, provide hybrid preview resources with the help of online teaching means prior to class, guide students to carry out efficient pre-class preview activities, as well as lay a good foundation for the improvement of follow-up teaching effect ${ }^{[6]}$. For example, in taking blood pressure, teachers can guide students to participate in online preview activities first. Teachers can record a short video that is consistent with the teaching content and upload it to the e-learning platform; then, when students preview independently through the e-learning platform, they should complete the preview task list, identify the problems during preview, and then provide feedback to the teachers through online messaging, so as to make the pre-class preview more targeted.

\subsection{Hybrid and flipped classroom practice}

In regard to the offline classroom teaching link, after students complete the pre-class preview task, teachers would then carry out classroom teaching activities according to the feedback of students' online preview, so as to help students gain a breakthrough in the difficulties faced while learning and strengthen their "harvest" in learning ${ }^{[7]}$. In this link, teachers can provide good learning references with the help of online and offline hybrid methods, relying on its characteristics of refined content and vivid images, further simplify their learning difficulties, as well as improve the efficiency of classroom learning. At the same time, teachers can make use of its simple operation and strong flexibility to create a hybrid flipped classroom, provide students with opportunities to explore knowledge, so as to lay a foundation for the development of their abilities, including autonomous learning and innovative practice, as well as enable higher vocational nursing English to realize the efficiency of classroom teaching with the help of micro classroom ${ }^{[8]}$. For example, with regard to the topic of "UTI (urinary tract infection) symptoms," teachers can design a micro class based on the pre-class preview feedback and then divide the students into two groups to guide them to learn relevant contents, play the roles of doctors and patients, respectively, as well as design a group of English dialogue to introduce UTI to patients. Each group can then be evaluated and guided in the correct manner, so as to achieve the flipped classroom teaching goal and lay the foundation for the development of students' English expression and thinking ability.

\subsection{Hybrid after-class consolidation}

From the perspective of previous educational development, the after-class consolidation link is related to the improvement of students' learning effectiveness ${ }^{[9]}$. However, in the teaching process, the after-class consolidation link of English teaching for nursing in higher vocational colleges is rare. Although there are many test exercises, it is easy to deflate students' learning enthusiasm and affect the development of classroom teaching. In this context, under the background of "Internet Plus Education," teachers can build a modern and personalized after-class consolidation platform based on online and offline hybrid teaching, so that students can independently review and consolidate after class, thus laying the foundation for the improvement of their comprehensive ability ${ }^{[10]}$. For example, after teaching the topic of "medical specialties," it is not a surprise that teachers would want to deepen students' understanding and knowledge mastery. With the help of internet technology, students can freely write English articles about medical specialties and upload them onto the online learning platform. Subsequently, teachers can provide targeted 
feedbacks to their articles. In the later collective teaching, teachers can then explain again to help students master a certain part of the content and improve the effectiveness of their learning.

\section{Conclusion}

In short, under the background of "Internet Plus Education," the online and offline hybrid teaching method in English teaching for nursing in higher vocational colleges has become the trend of innovative teaching. In this new era, teachers should face up to the connotation, concept, and significance of hybrid teaching as well as carry out innovative teaching while considering the problems existing in current classroom teaching, so as to provide students with a new normal of interesting, advanced, and efficient teaching. With the application of hybrid teaching, students can master English knowledge and professional knowledge, so as to lay a solid foundation for their English learning and the improvement of their professional quality.

\section{Disclosure statement}

The author declares that there is no conflict of interest.

\section{References}

[1] Liu J, 2021, Discussion on Employment Oriented Nursing English Teaching Reform in Higher Vocational Colleges. Comparative Study on Cultural Innovation, 5(24): 60-63.

[2] Cheng L, 2021, Application of Blended Teaching in Nursing English - Taking Changzhou Health Higher Vocational and Technical School as an Example. Teacher, 2021(28): 35-36.

[3] Han W, 2021, Application of Information Technology in Oral English Teaching of Nursing Specialty in Higher Vocational Colleges. English Square, 2021(08): 101-103.

[4] Jin J, 2020, Discussion on the Design of Online and Offline Mixed Teaching of English in Higher Vocational Colleges. Research on Continuing Education, 2020(03): 109-112.

[5] Wang Y, 2018, Exploration on the Mixed Teaching Mode of English Flipped Classroom in Higher Vocational Colleges Based on Mu Class - Taking Wuhan Vocational and Technical College as an Example. Journal of Nanchang Institute of Education, 33(05): 67-70.

[6] Peng H, 2016, Discussion on the Reform of Blended Teaching Mode of Public English in Higher Vocational Colleges Based on Internet Plus. Journal of Qingdao Vocational and Technical College, 29(03): 38-41, 46.

[7] Ning Y, Zha J, Shi F, et al., 2017, Innovation and Practice of Blended Teaching Mode of Flipped Classroom in Higher Vocational English Under the Mobile Network Environment. Vocational and Technical Education, 38(35): 39-41. DOI: 10.3969/j.issn.1008-3219.2017.35.012

[8] Yu L, Liu F, Li H, 2018, A New Mixed Teaching Strategy of Higher Vocational English Based on Flipped Classroom. Educational Academic Monthly, 2018(11): 104-111. DOI: 10.16477/j.cnki.issn167 4-2311.2018.11.012

[9] Chen Q, 2019, Multi Modal Vocational Nursing English Teaching Practice Under the Background of Internet Plus. Journal of Hubei Open Vocational College, 32(02): 151-152, 157.

[10] Yang H, 2020, Design and Implementation Analysis of Online and Offline Mixed Teaching Mode in Higher Vocational English. Overseas English, 2020(02): 272-273. 